\title{
Changing Organizational Culture for Enterprise Performance
}

\author{
${ }^{1}$ Adriana Tidor, ${ }^{2}$ Liviu Morar \\ ${ }^{1,2}$ Technical University Cluj-Napoca, Romania
}

\begin{abstract}
The purpose of this paper is to show the importance of organizational culture in improving the performance of Romanian small and medium enterprises(SMEs). The research was conducted in 40 SMEs inthe North-West area of the country. The method of research used was the survey. The instrument used was a questionnaire that included 35 organizational characteristics considered by the authors the most important. The main idea of the research was that after the employees complete the online questionnaire the manager can receive a complete report about the answers, underlyining the weaknesses and strengths of the organizational culture according to the answers. The evaluation of cultural weaknesses and strengths is made after a guideline established considering the scales included in the questionnaire. After this phase of the research, if the manager wishes we can provide him with a set of strategies to mend the problems(the weakenesses). This step is very important because many researches regarding organizational culture just diagnose the type of culture but do not offer solutions for the problems. Changing culture is a difficult task and a long- term one, but in our opinion change is more easy to achieve considering the special attributes of SMEs and the period in wich culture may be changed will be shorter. Any change within an organization must start with the change of culture.
\end{abstract}

Keywords: Enterprise performance, Organizational culture, Small and medium enterprises.

\section{Introduction}

Organizational culture is a quite new term for the Romanian enterprises. Few are the companies that take in count organizational culture when they elaborate the strategies and set the objectives for their organization. That is why few recognize the importance of organizational culture and the influence it has on the organizational performance. In a moment in wich the economic crisis daily dizolves dozens of enterprises, SMEs fight for survival. The author's belief is that this sector of the economy is the key of economic revival.

The research had as main purpose the analysis of organizational culture in 40 SMEs from the Cluj county and the observation of the link between organizational culture and the financial performances of the enterprises. Also the authors wanted to elaborate a methodological set of rules that can be applied to any enterprise not just to the ones in this study, in order to diagnose quick and efficient the main components of organizational culture, to detect the problems appeared and to take the best measures in order to mend the cultural problems and initiate the process of organizational change. In the recent years the researchers are in search of a model of demonstrating a link between organizational culture and enterprise performance. The direct linking between organizational

culture components and performance is not a new idea. But it is an idea that few managers take in count when defining the strategies of their enterprise. One can say that is difficult to link two notions so different such as organizational culture (a qualitative dimension) and per- formance(in most cases a quantitative dimension defined through indicators). Organizational culture through it's specific values influences directly the way objectives, policies and strate- gies are made in the enterprise. Organizational culture through it's elements contributes to the increase of the competitivity of the enterprise. As far as organizational culture means re- specting norms and ethics in the business, keeping and improving interpersonal relations, team work, keeping and developing traditions, creating and transmitting the most powerfull values and convictions, the competitivity of the enterprise is maintained or even improved. 
The objective of studying organizational culture is to help understand organizational life more. Understanding organizational life is important as it is widely acknowledged that organizational cultures have an impact upon company performance. The idea began with the simple observation that small and medium enterprises were very affected by the crisis, many facing bankrupcy.

Culture is a multi-dimensional concept that can be applied to firms, industries or nations. A review of existing literature yields an array of definitions of culture. By far one of the most widely accepted definition is proposed by Schein (2004), who defines organizational culture as "a pattern of shared basic assumptions that the group learned as it solved its problems of external adaptation and internal integration that has worked well enough to be considered valid, and therefore, to be taught to new members as the correct way you perceive, think, and feel in relation to those problems".

Culture matters. It matters because decisions made without awareness of the operative cul- tural forces may have unanticipated and undesirable consequences. Not only does culture reside within us individuals, but It is also the hidden force that divides most of our behavior both inside and outside organizations (Schein, 2004). The essence of culture is not what is visible on the surface. It is the shared ways groups of people understand and interpret the world. If culture is to be analyzed and managed, it is important that we be clear about what is meant by the term. Failure to clearly specify what "culture" is can result in confusion, misunderstanding and conflict about its basic function and importance (O’Reilly, 1996).

The authors wanted to present a software solution any manager could use, to rapidly assess some of the basic elements of organizational culture from his enterprise and get the best measures to address the weaknesses resulting from this analysis. It is not the first time this idea appears in researches. Many consulting firms have conducted surveys that were sent to firms to be completed online and then have made so-called cultural profiles, defining companies in a particular cultural group. However we notice that the researches are missing the other side, equally important to any assessment, the solutions for improvement.

Continuous performance must be the primary objective for any organization because only through performance organizations have the possibility to progress and evolve. When selecting to use financial performance indicators one of the motives was that using them is easier for a person outside the organization to evaluate performance using those indicators. And also the limited resources and refuse of the managers in helping us did not permit us to make a more deeper analysis of the enterprise performance.

SMEs have a more organic culture than big organizations. A small number of people are usually united under common beliefs and values and that means that in SMEs changing organizational culture should be easier. The most influence on the organizational values and beliefs in SMEs has the owner. This was the main reason we focused our research on the SMEs in Romania. The recent economic crisis had a bad influence on the financial performances of the majority of the enterprises in Romania. But the most hit sector was the sector SMEs. So in order to avoid future problems and to begin reconstruction organizational culture must be diagnosed and the change must begin with it. The authors consider that organizational culture change would be easier to achieve in SMEs and would not require 10-15 years as in big companies.

\section{Methodology}

The research was conducted with the aim of verifying one main hypothesis (the organizational culture influences the financial performances of the firm) and 35 secondary hypothesis, that were the same with the main characteristics included in the final questionnaire. The method used to collect data was the survey technique. The instrument used was the questionnaire sent through email to firms in the Cluj county. The online questionnaire was realised on the Google Docs platform. The questionnaire was structured in three parts. The first part contained 25 statements about the organization with responses possible on a Likert scale from 0 to 5 . The second part contained 20 organizational characteristics and the respondents were asked to give a note from 1 to 5 according to the importance in their organization of each characteristics. The final part contained questions about the organization including year of foundation, domain of activity and number of employees. The domain of activity for the enterprises used for this study is presented in chart 1. Chart 2 presents the size of the enterprises that participated to our research, in number of employees. 


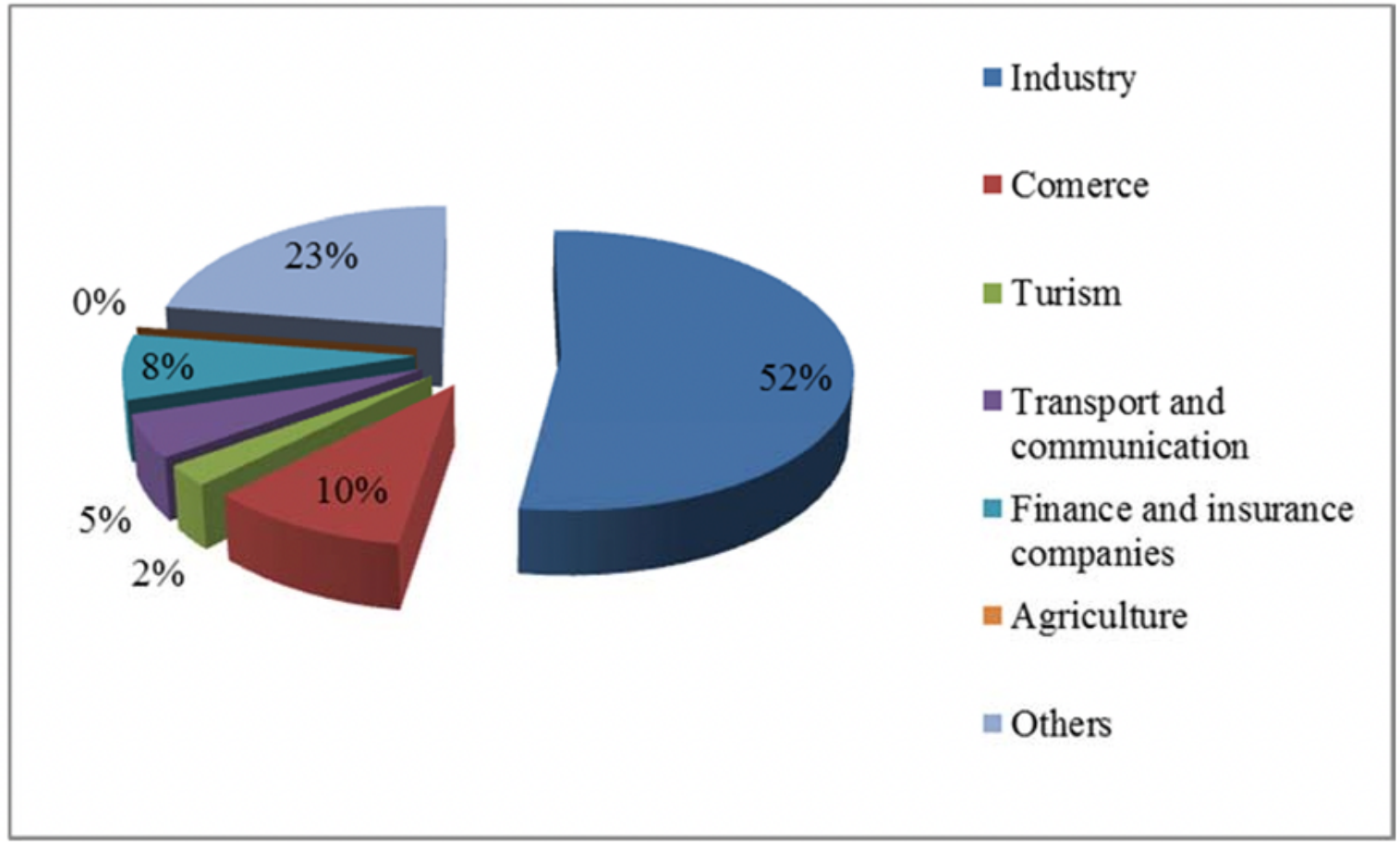

Chart 1: Domain of activity of the enterprises that participated in the research

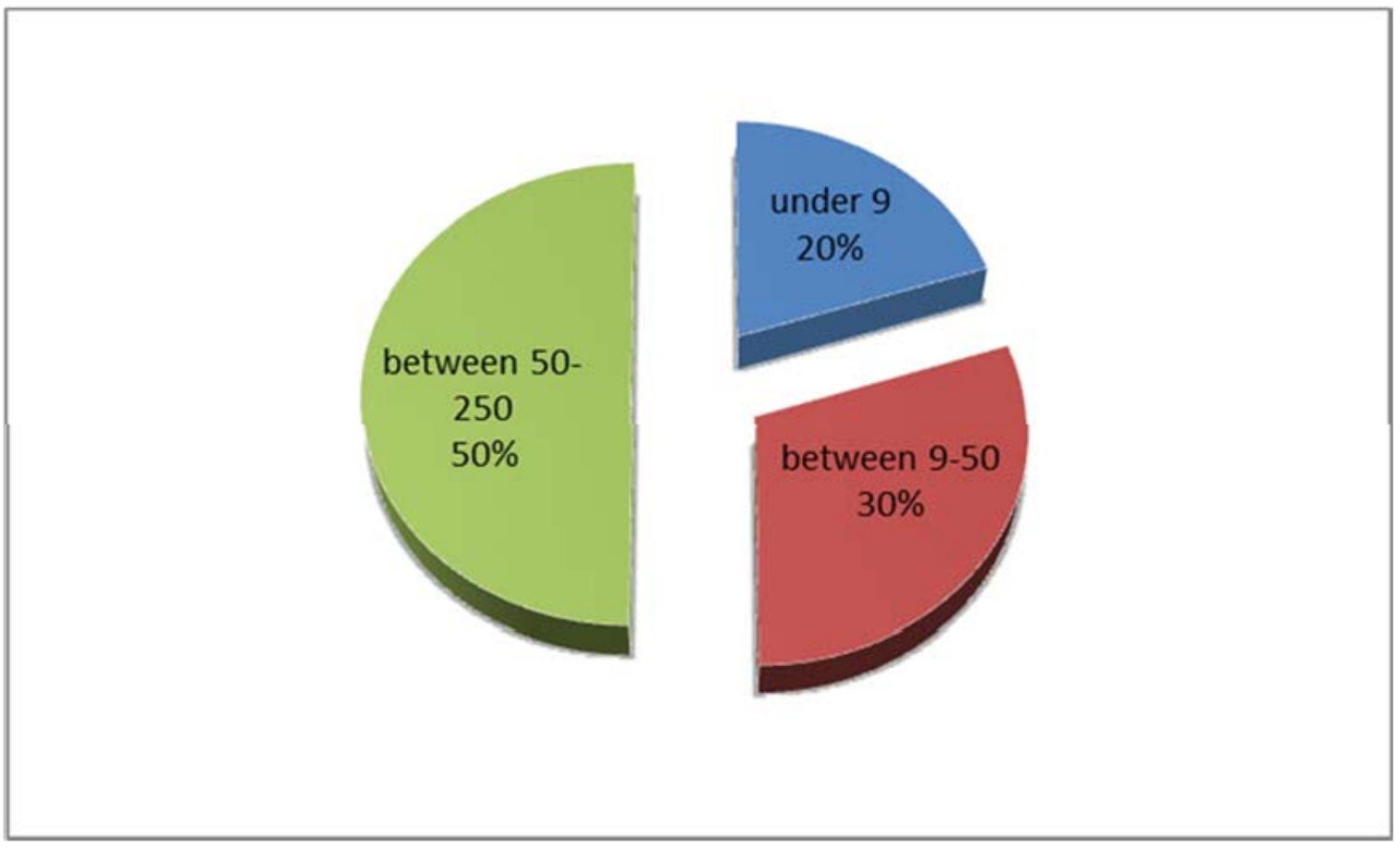

Chart 2: Size of the enterprises that participated in the research in number of employees

After observing the results of the organizational culture questionnaire for the first part the components with scores bellow 2,8 were considered weaknesses and the components with the scores above 3,7 were considered strengths. For the second part of the questionnaire strengths were considered the components with the scores over 3,7 and weaknesses those with scores below 3 .

The survey achieved a cultural profile of each company, and the results were grouped into strengths and weaknesses. This classification aims at differentiating the points where must be made changes to remedy the cultural issues. The study 
included an analysis of key performance indicators belonging to the SMEs considered thus observing that most companies have problems in terms of profit, which should be a warning. The economic crisis may be a motive for this problems, but evaluating the results obtained from questionnaires centralization it is observed that the same companies with the biggest problems have recorded the worst results in terms of organizational culture.

The guide for resolving the weaknesses was developed by the author in collaboration with several managers of SMEs that have problems to highlight the applicability of the guideline and the importance of continuing research in this area. Discussions with managers were conducted based on a interview draft with free answers and the topics were restricted to the characteristics of organizational culture contained in the questionnaire. The guideline contained the most important cultural characteristics, and these were presented in a booklet.

In order to evaluate the financial performances of the enterprise we used financial performance indicators.The performance indicators were calculated using the data on the Ministery of Finance site. The number of indicators was limited because on the site you can not find all the data needed in order to calculate all financial indicators. So the authors used the following performance indicators: return on gross business, return on net trade, the return on investment, return on equity, general liquidity ratio, acid test, financial leverage, rotation of total assets. In order to exemplify adequate the methodology used we will present the steps on a case study, underlyining the fact that this were the steps used for each of the 40 enterprises in the study. The conclusions will be presented generally.

\section{Results}

The enterprise on which we present the method is from the communication domain and has till now 20 years of activity in the field of IT components. The first step in our research was to look for the mission and values the leadership of the enterprise states on the web page that presents the enterprise. The mission stated was:

»Helping clients to capitalize their potential by providing advanced integrated solutions hardware - software communications and by personalizing the products and services depending on the needs of each customer.«

Declared values:

- $\quad$ Commitment to the client;

- $\quad$ Commitment to the employees;

- $\quad$ Commitment to the partners;

- $\quad$ Work environment that promotes teamwork;

- $\quad$ Jobs based on performance challenge;

- $\quad$ Various forms of training for job satisfaction;

- $\quad$ Listening carefully to customers.

The second step was to centralize the results of the questionnaires and to determine which of the cultural characteristics are strengths and which are weaknesses for this particular enterprise. Table 1 presents the results of this second step of the methodology.

Table 1: Strengths and weaknesses regarding organizational culture

\begin{tabular}{|l|l|}
\hline STRENGTHS & WEAKNESSES \\
\hline Stability & Low motivation \\
\hline Professional development for the employees & Lack of innovation \\
\hline Corectitude & Poor organization \\
\hline Good communication & Low adaptability \\
\hline Competitivity & \\
\hline Quality & \\
\hline Enthusiasm & \\
\hline The attachement for the organization is encouraged & \\
\hline The employees trust the leadership & \\
\hline Team work & \\
\hline Long term planning & \\
\hline Continuous improvement & \\
\hline Good reaction to the global economic crisis & \\
\hline Interest for the welfare of the employees & \\
\hline
\end{tabular}


After evaluating the organizational culture the third step was responsible for the evaluation of the financial performance indicators. Table 2 presents the eight performance indicators that could be calculated with the data available for years 2009, 2010 and 2011

Table 2: Performance indicators for the enterprise considered

\begin{tabular}{|c|c|c|c|}
\hline Indicator & $\mathbf{2 0 0 9}$ & $\mathbf{2 0 1 0}$ & $\mathbf{2 0 1 1}$ \\
\hline $\mathbf{R C}_{\mathbf{b}}$ & 0.09 & 0.11 & 0.13 \\
\hline $\mathbf{R C}_{\mathbf{n}}$ & 0.08 & 0.1 & 0.11 \\
\hline $\mathbf{R I}$ & 0.17 & 0.29 & 0.19 \\
\hline $\mathbf{R F}$ & 0.34 & 0.67 & 0.63 \\
\hline $\mathbf{R L G}$ & 2.17 & & 1.78 \\
\hline $\mathbf{R R L}$ & 1.88 & 1.74 & 1.46 \\
\hline PF & 2.07 & 1.57 & 3.26 \\
\hline ROA & 2.09 & 2.30 & 1.71 \\
\hline
\end{tabular}

One can easily see from the data presented that indeed this enterprise has no problems beacuse of the global economic crisis and the values stated by the leadership are present also in the category of the strengths after evaluating the questionnaires. Also we can observe that the weknesses are points that characterize the whole sector of SMEs in our country such as lack of innovation and adaptability. But this enterprise does not have such big problems concerning organiazational culture and this problems may be mended by initializing an organizational change, starting with the structure because this was one of the weaknesses.

Regarding the fact that organizational culture influence4s organizational performance we can say at this point that we strongly believe that the fact that this enterprise has more strengths than weaknesses and that the financial indicators have good values considering the economic state of our country is the result of the positive influence that a strong organizational culture has on the financial results of an enterprise. To underline the fact that this a case study and that each organization has it's own culture and characteristics. We consider that this guideline in four steps can be applied to any enterprise and can be the first step in initializing the organizational cultural change.

\section{Conclusion}

The most important point of this research is to highlight the characteristics of the organiza- tional culture in Romanian SMEs and to initiate an analysis that can prove that were there are strong cultures there is performance. These data collected and analysed can not be gen- eralised. After analyzing the enterprises we could observe that many have financial problems due to the global economic crisis. Our important point is that if an organization seeks to make changes to increase performance the first point is to analyze and change organizational culture. Without a strong culture performance can not be at the levels desired. The financial indicators show the economic problems that SMEs had to face during this turbulent period of crisis and the cultural analysis revealed the fact that problems also come from inside the organization.One can not achieve performance when employees are not involved in decision making, when procedures are not respected, when innovation is not a priority, when people think negative or when appears any of the weaknesses we found in the enterprises. Without managers understanding the importance of organizational culture the step ahead con not be made and performance in the true meaning will remain just a dream. Organizational culture is the most important component of the organization. It is imperative to known the elements of organizational culure so that we can use the 
strengths for competitive advantage. It is not simple to diagnose organizational culture and it can not be modified in one year, but the authors consider that without diagnosing and changing organizational culture the organization can not achieve performance. Change must begin with the culture. It is very important for every manager to know to use the strengths of his own enterprise and the weaknesses of the competitors.

\section{References}

- Boian, N. (2007). Diagnostic of competitive position of small and middle size companies. In International Conference on Economic Engineering and Manufacturing Systems, Braşov, Romania (pp. 212-215).

- Bucurean, M., Costin, M. and Marcu, M. (2011). Culture - a factor that determines the entreprenurial behaviour. Annals of the University of Oradea, 20(1), 526-529.

- Cîmpeanu, M. and Pîrju, I. (2010). The specificity of organizational culture in European Management. In 5th International Conference European Integration: Realities and Perspectives (pp. 290-295). Galaţi.

- Che Rose, R. and Rumar, N. (2008). Organizational culture as a root of performance improvement: Research and recommendations. Contemporary Management Research 4(1), 45-56.

- Denison, D. (1995). Toward a theory of organizational culture and effectiveness. Journal of Organization Science, 6(2), 205-223.

- Gruian, M. (2011). Modern factors that enhance company's financial performance.

- Annals of the University of Oradea, 1(2), 169-175.

- Henri, J. F. (2006). Organizational culture and performance measurement systems.

- Accounting, Organization and Society, 31(1), 77-103.

- Inglehart, R. and Baker, W. (2000). Modernization, cultural change and the persistence of traditional values. American Sociological Review, 65(1), 19-51.

- Janicijevic, N. (2011). Methodological approaches in the research of organizational culture. Economic Annals of the Belgrade University, 46(189), 69-99.

- Janicijevic, N. (2012). The influence of organizational culture on organizational preferences towards the choice of organizational change strategy. Economic Annals of the Belgrade University, 57(193), 25-51.

- O'Reilly, C. (1996). Corporations, culture and commitment: motivation and social control in organizations. Research in Organizational Behavior, 18, 157-200.

- Schein, E. (2004). Organizational culture and leadership. San Francisco: Jossey Bass Publishing.

- Jidor, A. and Morar, L. (2012). Organizational culture the key to the financial performance of Romanian SMEs. In 3rd RMEE International Conference Proceedings, Cluj-Napoca, Romania.

- Jidor, A. (2012). Researches and contributions on the role of organizational culture in the management of small and medium enterprises (Doctoral dissertation). Cluj-Napoca: [A.Jidor].

- Jidor, A., Gelmereanu, C., Baru, P. and Morar, L. (2012). Diagnosing organizational culture for SME performance. In Emerging Markets Queries in Finance and Business 2012, Târgu-Mureş, Romania. 